\title{
Preferencije učenika prema aktivnostima i sadržajima u nastavi Glazbene kulture
}

Jasna Šulentić Begić*

jsulentic-begic@uaos.hr

https://orcid.org/0000-0003-4838-0324

Amir Begic ${ }^{* * *}$

abegic@uaos.hr

https://orcid.org/0000-0003-2152-9563

Ivana Pušićc***

ivana.pusic@hotmail.com

https://orcid.org/0000-0002-8386-2137 https://doi.org/10.31192/np.18.1.13

UDK: 78:37.091.33

37.091.33:78

001.891.5-053.6

Izvorni znanstveni rad / Original scientific paper Primljeno: 20. siječnja 2020. Prihvaćeno: 11. ožujka 2020.

Od školske godine 2019./2020. nastava Glazbene kulture treba se realizirati prema Kurikulumu nastavnog predmeta Glazbena kultura za osnovne škole i Glazbena umjetnost za gimnazije koji će tijekom tri godine ući u sve razrede osnovne škole. U nastavi se realizira otvoreni kurikulum koji učiteljima omogućuje da učenje i podučavanje prilagođavaju interesima i sposobnostima učenika te vlastitim sklonostima. U okviru rada provedeno je istraživanje čiji je cilj bio utvrditi preferencije učenika prema različitim aktivnostima i sadržajima u nastavi Glazbene kulture te otkriti postoje li razlike u preferencijama s obzirom na razred, spol učenika te (ne)pohadanje izvannastavne/izvanškolske glazbene aktivnosti. Istraživanje, koje se odvijalo tijekom 2018. godine, obuhvatilo je 280 ispitanika, tj. anketirani su učenici četvrtog, šestog i osmog razreda. Rezultati pokazuju da učenici imaju pozitivan stav prema nastavi Glazbene kulture i da najviše preferiraju pjevanje, a zatim slušanje glazbe i glazbene igre. Međutim, zastupljenost aktivnosti i sadržaja, osim pjevanja, nije proporcionalna učeničkim preferencijama. Preferencije prema glazbenim aktivnostima s obzirom na spol učenika pokazuju kako se pojedine aktivnosti nalaze na istom mjestu i kod učenika i kod učenica. Također, slušanje glazbe više preferiraju učenici koji glazbenu izvanna-

\footnotetext{
" Izv. prof. dr. sc. Jasna Šulentić Begić, Akademija za umjetnost i kulturu u Osijeku, Kralja Petra Svačića 1/F, HR-31000 Osijek.

** Doc. dr. sc. Amir Begić, Akademija za umjetnost i kulturu u Osijeku, Kralja Petra Svačića 1/F, HR-31000 Osijek.

*:**: Ivana Pušić, mag. mus., Osnovna škola Ivana Kozarca, Dr. Franje Račkog 30, HR-32270 Županja.
} 
stavnu/izvanškolsku aktivnost nisu polazili ili je ne polaze. Zaključno, smatramo da bi se glazbene preferencije učenika trebale uzeti u obzir prilikom osmišljavanja nastavnih jedinica, izbora glazbe i organiziranja i izvođenja nastave.

Ključne riječi: aktivnosti i sadržaji, Glazbena kultura, otvoreni model/kurikulum, preferencije učenika.

\section{Uvod}

Školske godine 2006./2007. u hrvatske osnovne škole uveden je Nastavni plan i program za osnovne škole $e^{1} \mathrm{u}$ okviru HNOS-a (Hrvatski nacionalni obrazovni standard). Od tada se nastava Glazbene kulture organizira prema otvorenom modelu u kojem je samo jedna aktivnost središnja i ujedno obavezna u nastavi Glazbene kulture, a to je slušanje glazbe. ${ }^{2}$ Od školske godine 2019./2020. nastava Glazbene kulture treba se realizirati prema Kurikulumu nastavnog predmeta Glazbena kultura za osnovne škole i Glazbena umjetnost za gimnazije, ${ }^{3}$ koji će tijekom tri godine ući u sve razrede osnovne škole i gimnazije. Otvoreni model nastave glazbe se i dalje realizira pod nazivom otvoreni kurikulum koji učiteljima omogućuje da učenje i podučavanje prilagođavaju interesima i sposobnostima učenika te vlastitim sklonostima. Također, otvoreni kurikulum podrazumijeva visok stupanj slobode u odabiru i oblikovanju nastavnih sadržaja, primjeni različitih strategija i metoda učenja i poučavanja, kao i različitih pristupa vrednovanju. ${ }^{4}$

Glazbene aktivnosti i sadržaji u okviru Kurikuluma organizirane su u okviru tri domene (nastavna područja): Slušanje i upoznavanje glazbe, Izražavanje glazbom i uz glazbu i Glazba u kontekstu. Domena Slušanje i upoznavanje glazbe, kao što i sam naziv kaže, jest upoznavanje glazbe pomoću audio i videozapisa te mogući neposredan susret učenika s glazbom. U okviru domene Izražavanje glazbom i uz glazbu učenici izvode glazbene aktivnosti: pjevanje, sviranje, glazbene igre, glazbeno stvaralaštvo i pokret uz glazbu. S obzirom na otvoreni kurikulum nastave glazbe, učitelj će nekoj od navedenih aktivnosti dati veći ili manji naglasak. To znači da se sve navedene aktivnosti, za razliku od obveznog Slušanja i upoznavanja glazbe, ne moraju organizirati. U okviru treće domene, tj. Glazbe u kontekstu, učenici upoznaju društveno-povijesni i kulturni kontekst glazbe, različita značenja i funkcije glazbe te vrste i žanrove glazbe. Ukratko, treća domena objedinjuje muzikološke i glazbene sadržaje. ${ }^{5}$

\footnotetext{
${ }^{1}$ Usp. MINISTARSTVO ZNANOSTI, OBRAZOVANJA I ŠPORTA, Nastavni plan i program za osnovnu školu, Zagreb, MZOŠ, 2006; (dalje: Nastavni plan).

${ }^{2}$ Usp. isto, 66.

${ }^{3}$ Usp. MINISTARSTVO ZNANOSTI I OBRAZOVANJA, Kurikulum nastavnog predmeta Glazbena kultura za osnovne škole i Glazbena umjetnost za gimnazije, Zagreb, MZO, 2019; (dalje: Kurikulum).

${ }^{4}$ Usp. isto, 3.

${ }^{5}$ Usp. isto, 4.
} 


\section{Sadržaji i aktivnosti nastave Glazbene kulture}

S obzirom na to da se u nastavi Glazbene kulture realiziraju različiti sadržaji i glazbene aktivnosti, koji su više ili manje specifični, u radu će se izložiti razmišljanja različitih autora te rezultati istraživanja vezanih za pjevanje, sviranje i glazbeno opismenjivanje, stvaralaštvo, glazbene igre i ples/pokret te slušanje glazbe i muzikološke sadržaje.

\subsection{Pjevanje}

Pjevanje je najelementarniji, najspontaniji i najprirodniji način glazbenog ponašanja čovjeka, ${ }^{6}$ a u nastavi glazbe to je najčešća aktivnost. ${ }^{7}$ Razlog što se $u$ nastavi najviše provodi pjevanje je taj što se u toj aktivnosti velik broj učitelja primarnog obrazovanja osjećaju najkompetentnijima, ${ }^{8}$ no i stoga što učenici najviše vole pjevanje u usporedbi s ostalim aktivnostima. ${ }^{9}$ Od školske godine 2006./2007., stupanjem na snagu Nastavnog plana, pjevanje više nije središnja, nego izabrana aktivnost, a učestalost pjevanja u nastavi Glazbene kulture ovisi o sklonostima učitelja, interesima učenika te zajedničkom dogovoru. I prema Kurikulumu učitelj će pjevanju dati veći ili manji naglasak s obzirom na interese i sposobnosti učenika te vlastite sklonosti. Učitelj samostalno odabire pjesme: autorske (umjetničke, za djecu, popularne - evergreen) i tradicijske. Treba voditi računa o zanimljivosti i umjetničkoj vrijednosti pjesama, interesima i dobi učenika, težini pjesama, jasnoći teksta i primjerenosti sadržaja. Naime, učenicima pjesma treba biti zanimljiva jer se u protivnom tijekom pjevanja neće truditi i stoga im se neće razviti pjevačke sposobnosti. ${ }^{10}$ Stoga učitelj treba predstaviti učenicima nekoliko pjesama omogućujući im izbor najzanimljivije. Dajući im mogućnost da odlučuju i utječu na odabir pjesme učitelj će u učenika povećati interes i motivaciju za pjevanjem.

${ }^{6}$ Usp. Pavel ROJKO, Metodika nastave glazbe. Teorijsko-tematski aspekti, Osijek, Sveučilište J. J. Strossmayera, Pedagoški fakultet, 2012, 54.

7 Usp. Jere L. FORSYTHE, Elementary student attending behavior as a function of classroom activities, Journal of Research in Music Education, 25 (1977) 228-239; Randall S. MOORE, Effects of age, sex, and activity on children's attentiveness in elementary school music classes, u: Clifford K. MADSEN, Caren A. PRICKETT (ur.), Applications of research in music behavior, Tuscaloosa, University of Alabama Press, 1987, 26-31, prema Charlotte P. MIZENER, Attitudes of Children toward Singing and Choir Participation and Assessed Singing Skill, Journal of Research in Music Education, 41 (1993) 3, 233-245, 233.

${ }^{8}$ Usp. Jasna ŠULENTIĆ BEGIĆ, Amir BEGIĆ, Otvoreni model nastave glazbe u razrednoj nastavi, Školski vjesnik, 64 (2015) 1, 112-130, 119.

${ }^{9}$ Usp. Chelcy L. BOWLES, Music Activity Preferences of Elementary Students, Journal of Research in Music, Deep Education, 46 (1998) 2, 193-207, 195; Mizener, Attitudes of Children toward Singing..., 241.

${ }^{10}$ Usp. Debra HEDDEN, An Overview of Existing Research About Children's Singing and the Implications for Teaching Children to Sing, Update. Applications of Research in Music Education, 30 (2012) 2, 52-62, 59. 
Pjevanje velikog broja tradicijskih pjesama u nastavi Glazbene kulture se kritizira, tj. zagovara se brojčano smanjivanje takvih pjesama. ${ }^{11}$ Unapređenje izbora tradicijskih pjesama podrazumijeva »njihovu svojevrsnu etnomuzikološku reviziju prema folklornim regijama u kojoj bi se broj pjesama sveo na približno sličnu količinu za svaku regiju«. ${ }^{12} \mathrm{Da}$ treba smanjiti broj tradicijskih pjesama govore i rezultati istraživanja, ${ }^{13}$ a koji pokazuju da učenici najmanje vole pjevati tradicijske, a najviše popularne i dječje pjesme. Stoga se mogu pjevati tradicijske pjesme koje su obradili popularni glazbenici jer su učenicima već poznate i radije će ih pjevati.

U nastavi glazbe često se teži funkcionalnom pjevanju, no takav način pjevanja nema estetske elemente i treba ga izbjegavati. ${ }^{14}$ Pri pjevanju, u nastavi Glazbene kulture treba težiti umjetničkom pjevanju, tj. lijepom pjevanju koje će biti temelj pjevanja u školskog pjevačkom zboru. Stoga se i u Kurikulumu navodi da, radi njegovanja glasa i razvijanja kulture lijepoga pjevanja, učenike treba kontinuirano poticati na aktivno sudjelovanje u aktivnosti pjevanja. Učitelja obvezuje samo naznačeni broj pjesama koji je naveden u svakom razredu kao preporuka za ostvarenje odgojno-obrazovnog ishoda za domenu Izražavanje glazbom i uz glazbu. Od prvog do trećeg razreda učenici bi tijekom školske godine trebali naučiti najmanje 10 novih pjesama, od četvrtog do šestog najmanje 15, dok je za sedmi i osmi razred preporučeno 10 pjesama. ${ }^{15}$ Više autora ističu da se $u$ višim razredima osnovne škole smanjuje pozitivan stav prema pjevanju. ${ }^{16}$ Ovo može biti posljedica odrastanja te pjevanje treba smanjiti, no ne i sasvim odbaciti.

U nastavi Glazbene kulture dugo se prakticiralo usvajanje pjesme po notama, no treba ga izbjegavati jer podrazumijeva primjenu znanja i umijeća koja učenici općeobrazovne škole nemaju. Stoga pjesme treba uvijek usvajati po sluhu. ${ }^{17}$ U Kurikulumu se navodi da pjesme treba usvajati metodom učenja po sluhu. Učitelj pritom na glazbalu izvodi harmonijsku pratnju, ne preporučuje

${ }^{11}$ Usp. Rojko, Metodika nastave glazbe..., 60.

${ }^{12}$ Antoaneta RADOČAJ-JERKOVIĆ, Pjesma i pjevanje u razredu u općeobrazovnoj školi, Tonovi, 59 (2012) 32-82, 42.

${ }^{13}$ Usp. Jasna ŠULENTIĆ BEGIĆ, Pjevanje kao izabrana aktivnost otvorenog modela nastave glazbe, u: Tomislav VRANDEČIĆ, Ana DIDOVIĆ (ur.), Monografija umjetničko-znanstvenih skupova 2007.-2009. Glas i glazbeni instrument u odgoju i obrazovanju, Zagreb, Učiteljski fakultet Sveučilišta u Zagrebu - Europski centar za napredna i sustavna istraživanja, 2010, 6067, 63.

${ }^{14}$ Usp. Rojko, Metodika nastave glazbe..., 62.

${ }^{15}$ Usp. Kurikulum...,15, 17, 19, 21, 23.

${ }^{16}$ Usp. Kenneth H. PHILLIPS, Randall E. AITCHISON, The effects of psychomotor skills instruction on attitude toward singing and general music among students in grades four-six, Bulletin of the Councilfor Research in Music Education, 137 (1998) 32-42, 32; Josef ECKHARDT, Helmut E. LÜCK, Das Petitium nach dem Schulmusikunterricht, Musik und Bildung, 7 (1976) 8, 365-377, 367; Friedrich KLAUSMEIER, Jugend und Musik im technischen Zeitalter, Bonn, H. Bouvier u. Co. Verlag, 1968, 205.

${ }^{17}$ Usp. Pavel ROJKO, Metodika glazbene nastave - praksa I. dio, Zagreb, Jakša Zlatar, 2004, 167. 
se pjevanje uz matricu. Promatrajući nastavu glazbe primarnog obrazovanja u nekoliko osnovnih škola zaključilo se da je pjevanje najčešća aktivnost u nastavi Glazbene kulture..$^{18}$ Međutim, usvajanje pjesme se ne provodi pravim metodičkim postupkom jer se samo u polovici promatranih sati pjesma učila usvajanjem pjesme po sluhu. Učitelji koji nisu provodili učenje pjesme na taj način najčešće su jednokratno reproducirali pjesmu putem uređaja, dok su neki učitelji pjevali pjesmu bez instrumentalne pratnje. Samo nekoliko učitelja je razgovaralo o tekstu pjesme s učenicima, što je izrazito važno u toj dobi jer je moguće da učenicima sadržajno nije razumljiv tekst pjesme. Na taj način pjesma im se neće svidjeti i neće se s njom »zbližiti«.

Ocjenjivanje pjevanja ne bi trebalo biti problem, no pri tome treba imati u vidu da je u pjevanju važniji proces od krajnjeg rezultata jer postignuće ovisi o glazbenim sposobnostima koje utječu na razinu uspješnosti učenika. Učenike s manje razvijenim glazbenim sposobnostima učitelj ne ocjenjuje individualno već tijekom skupnog muziciranja, tj. vrednuje i ocjenjuje njihov odnos prema aktivnosti i njihovu uključenost. Prema Kurikulumu takav učenik ne smije dobiti negativnu povratnu informaciju, tj. nižu ocjenu ako pjeva netočno, naročito u nižim razredima osnovne škole, već smjernice u čemu je bio uspješan i kako može poboljšati svoju izvedbu.

\subsection{Sviranje i glazbeno opismenjivanje}

Nakon stare Grčke, u kojoj je sviranje na instrumentima bilo obvezni dio glazbenog odgoja, sviranje se ponovno u školama pojavilo tek u 19. stoljeću, no uvođenje instrumenata nije bilo masovno. Postupno uvođenje instrumenata počinje početkom 20. stoljeća. ${ }^{19}$ Nastava Glazbene kulture u Hrvatskoj slijedi europsku tradiciju sviranja u osnovnoj školi, a dijeli se na sviranje u redovnoj nastavi glazbe i sviranje $u$ ansamblu ili orkestru koje se organizira kao izvannastavna aktivnost. Sviranje se u našem nastavnom planu i programu uvelo 1958. godine, a kao aktivnost postoji i u Kurikulumu u okviru domene Izražavanje glazbom i uz glazbu. Predlaže se da za potrebe sviranja učenici koriste tjeloglazbu, dječji instrumentarij, melodijske udaraljke ili druga jednostavnija melodijska glazbala, standardna glazbala te proizvode zvuk na elektroničkim instrumentima i/ili na računalu. U aktivnom muziciranju učenika, tj. sviranju, kao i kod pjevanja, važniji je proces od krajnjeg rezultata jer postignuće u tim aktivnostima ovisi o glazbenim sposobnostima koje utječu na razinu uspješnosti učenika. Također, učenike se može poučiti notnom pismu za potrebe sviranja te potaknuti na korištenje računalnih programa za notografiju. Usvajanje glazbene pismenosti za učenike općeobrazovnih škola jedino ima smisla ako se notno pismo usvaja za

\footnotetext{
${ }^{18}$ Usp. Jasna ŠULENTIĆ BEGIĆ, Veronika BIRTIĆ, Otvoreni model nastave glazbene kulture u primarnom obrazovanju u nekim osječkim osnovnim školama, Tonovi, 60 (2012) 72-84, 82.

${ }^{19}$ Usp. Rojko, Metodika nastave glazbe..., 64.
} 
potrebe sviranja. U slučaju da se sviranje ne provodi korištenjem instrumenata, onda notno pismo treba upoznavati samo kao glazbeni fenomen, odnosno informativno i to retrogradnim putem. Upoznavanje glazbenoga pisma treba shvaćati kao igru u kojoj će učenici uvidjeti osnove glazbene pismenosti. Ta »znanja« ne smiju biti predmetom provjeravanja i ocjenjivanja. ${ }^{20}$

Škole nisu opremljene udaraljkama, a sviranje je, nakon pjevanja, na drugom mjestu po omiljenosti kod učenika četvrtih razreda, dok je kod učenika osmih razreda na trećem mjestu. ${ }^{21} \mathrm{U}$ nastavi se koriste improvizirane udaraljke koje stvaraju buku i djeluju neestetski, pa se umjesto toga predlaže pljeskanje, kucanje ili lupkanje. ${ }^{22}$ Improvizirane udaraljke, tj. praksa izrade »instrumenata« od konjskih potkova, čavala, kutija ispunjenih kamenčićima i sl. ne može se tumačiti nikakvim glazbenim argumentima. ${ }^{23}$ Osim pjevanja, učenici su u prva tri razreda osnovne škole najviše motivirani za sviranje, a učitelji su prilikom promatranja upravo tim aktivnostima pridavali najviše pozornosti na pojedinim satima. ${ }^{24}$ Sviranje je najomiljenija aktivnost kod učenika svih uzrasta, od najmlađih učenika pa sve do petog razreda..$^{25}$ Interes za blok-flaute i Orffov instrumentarij i njihov jednostavan način sviranja prestaje $s$ jedanaestom godinom života i u toj dobi djeci treba ponuditi neke druge instrumente. ${ }^{26}$ Sviranje u razredu nema umjetničku vrijednost, ne pridonosi razvoju glazbenog ukusa, niti pomaže razumijevanju glazbe pa bi sviranje trebalo biti neobvezatna aktivnost koja će se provoditi kao igra. ${ }^{27}$ Ovomu se pridodaje argument da škole ne posjeduju kvalitetne instrumente nego plastične igračke te da je jedini pravi argument $\mathrm{u}$ korist sviranja $\mathrm{u}$ nastavi glazbe $\mathrm{u}$ skladu sa psihološkim načelom nastave glazbe, tj. da dijete želi biti aktivno i želi svirati. ${ }^{28}$

\subsection{Glazbeno stvaralaštvo, glazbene igre i ples/pokret}

U Kurikulumu se navodi da je stvaralaštvo važan element u procesu učenja jer potiče kreativnost u užem i širem smislu. Učitelj će organizirati stvaralačko izražavanje učenika u aktivnostima pjevanja, sviranja, plesa, pokreta te upora-

\footnotetext{
${ }^{20}$ Usp. Rojko, Metodika nastave glazbe..., 53.

${ }^{21}$ Usp. Snježana DOBROTA, Ivana OBRADOVIĆ, Stavovi učenika osnovne škole prema glazbi i nastavi glazbe, Školski vjesnik, 61 (2012) 1-2, 115-131, 124.

${ }^{22}$ Usp. Šulentić Begić, Birtić, Otvoreni model nastave..., 80.

${ }^{23}$ Usp. Zlatko GRGOŠEVIĆ, Opći principi muzičkog opismenjavanja u osnovnoj školi, Muzika i škola, 4 (1966) 132-137, 136.

${ }^{24}$ Usp. Jasna ŠULENTIĆ BEGIĆ, Tihana KUJEK, Slušanje glazbe u nastavi i udžbenicima glazbene kulture u prvim trima razredima osnovne škole, Tonovi, 69 (2017) 37-47, 45.

${ }^{25}$ Usp. Bowles, Music Activity Preferences..., 198.

${ }^{26}$ Usp. Klausmeier, Jugend und Musik im technischen Zeitalter..., 207.

${ }^{27}$ Usp. Rojko, Metodika nastave glazbe..., 69.

${ }^{28}$ Usp. Hermann REGNER, Einführungsvortrag. Symposion Orff Schulwerk 1980., Salzburg, Hochschule für Musik und darstellende Kunst Mozarteum in Salzburg - Orff-Institut, 1980, 13-15, prema Rojko, Metodika nastave glazbe..., 68.
} 
be IKT-a samostalno ili u skupini. Ideja glazbenog stvaralaštva u nastavi glazbe u osnovnoj školi prvi put se uvodi nakon zahtjeva J. J. Rousseaua da dječak Emil sam izmišlja pjesme (Émile: ou, de l'éducation). ${ }^{29}$ Carl Orff improvizaciju smatra posebnom aktivnošću za koju se učitelj mora pažljivo pripremiti jer najmanje smije improvizirati upravo u improvizacijskim vježbama učenika. Također, naglašava da improviziranje na instrumentu na kojem se ne zna svirati nije moguće, da tvorevine učenika ne treba smatrati originalnima te smatra da se potpuno slobodna, odnosno nevezana improvizacija treba izbjegavati jer će vjerojatno biti neuspješna. ${ }^{30} \mathrm{U}$ hrvatskim nastavnim programima glazbeno stvaralaštvo se prvi put pojavljuje 1951. godine. Iako nema posebnih objašnjenja, jasno je da ovaj program, ne spominjući pojam svjesnog glazbenog stvaralaštva, navodi upravo takve aktivnosti: glazbeni odgovor na učiteljevo glazbeno pitanje, male glazbene cjeline od četiri i od osam taktova. ${ }^{31}$ Kao primjer dječjeg glazbenog stvaralaštva i problema u njegovoj realizaciji navode se dječje melodijske improvizacije. ${ }^{32}$ Osnovni preduvjet za komponiranje logične i lijepe melodije je poznavanje osnovnih harmonijskih i formalnih zakonitosti njene izgradnje, što učenici nemaju.

Prema Kurikulumu učenik sudjeluje u aktivnostima glazbenog stvaralaštva i različitim glazbenim igrama, $t j$. $u$ igrama koje uključuju pjevanje i/ili druge aktivnosti izvođenja glazbe te igrama uz slušanje glazbe koje učenike potiču na ples i pokret i služe kao sredstvo ponavljanja i utvrđivanja različitih »glazbenih znanja«. Ističe se da glazbene igre imaju važnu primjenu u prvom i drugom odgojno-obrazovnom ciklusu jer mogu pomoći pri stvaranju opuštenog ozračja u razredu, doprinose zanimljivosti, uklanjaju monotoniju i učenici će stoga biti pažljiviji. Osim toga, pomoću njih učenici nesvjesno usvajaju glazbena znanja i vještine, a najvažniji argument za njihovo uvođenje u nastavu je taj da glazbene igre utječu na razvoj glazbenih sposobnosti učenika. Jedno je straživanje pokazalo da učitelji primarnog obrazovanja najviše provode igre uz pjevanje, zatim igre uz ritmove, a najmanje igre uz slušanje glazbe. ${ }^{33}$ Da mlađim učenicima treba omogućiti kretanje uz glazbu pokazalo je i istraživanje koje je utvrdilo da mlađa djeca uglavnom pozitivno reagiraju na sve glazbene aktivnosti, ali postoje preferencije prema kretanju uz glazbu temeljenom na igri. ${ }^{34}$ Stoga i Kurikulum predlaže da se učenik izražava pokretom uz glazbu prateći glazbeno-izražajne sastavnice i/ili izvodeći plesnu koreografiju i/ili oblikujući nove plesne strukture. Ples je vrlo popularna aktivnost među učenicima i sastavni je

\footnotetext{
${ }^{29}$ Usp. Rojko, Metodika nastave glazbe..., 100.

${ }^{30}$ Usp. Wilhelm KELLER, Einführung in die Musikfür Kinder. Orff-Schulwerk, Meinz, B. Schott's Sohne, 1963, 29.

${ }^{31}$ Usp. Rojko, Metodika nastave glazbe..., 101.

${ }^{32}$ Usp. Snježana DOBROTA, Glazbena nastava u razrednoj nastavi, Tonovi, 39 (2002) 67-79, 78.

${ }^{33}$ Usp. Šulentić Begić, Begić, Otvoreni model nastave glazbe..., 125.

${ }^{34}$ Usp. Nita TEMMERMAN, An investigation of the music activity preferences of pre-school children, British Journal of Music Education, 17 (2000) 1, 51-60, 51.
} 
dio mnogih europskih kurikuluma nastave glazbe ${ }^{35}$ te ima utjecaj na estetski razvoj učenika. ${ }^{36}$

\subsection{Slušanje glazbe i muzikološki sadržaji}

U hrvatskim nastavnim planovima i programima slušanje se prvi put uvodi 1950. godine, no samo kao preporuka jer program nije sadržavao posebne zahtjeve, a osim toga škole nisu bile opremljene adekvatnim sredstvima i pomagalima za reprodukciju glazbe. Školske godine 2006./2007., uvođenjem Nastavnog plana, slušanje glazbe postaje središnja i jedina obvezna aktivnost u nastavi Glazbene kulture. I u Kurikulumu to je prevladavajuća aktivnost nastave glazbe, tj. domena Slušanje i upoznavanje glazbe provlači se kroz sve cikluse, odnosno sve razrede osnovne škole i gimnazije. Ističe se da se u nastavi glazbe sve relevantne aktivnosti temelje na slušnom iskustvu koje pruža brojne mogućnosti za estetski odgoj učenika. Muzikološki se sadržaji upoznaju slušanjem glazbenog djela, tj. muzikološki sadržaji koji se ocjenjuju trebaju biti rezultat slušnog upoznavanja glazbe. Učenike treba upoznati s glazbenim djelima različitih razdoblja, stilova, vrsta i žanrova, da bi se uspostavila vrijednosna mjerila za estetsko i kritičko doživljavanje glazbe i kod učenika razvio glazbeni ukus. Naime, slušanje glazbe u nastavi glazbe možda će biti presudno za kulturu slušanja odrasle osobe. ${ }^{37}$ Škola može i treba utjecati na glazbeni ukus društvene zajednice. ${ }^{38}$

Učenici mlađe dobi imaju pozitivnije stavove prema slušanju umjetničke glazbe nego učenici starije dobi. ${ }^{39}$ Isto smatraju i Dobrota i Mikelić, no njihovo je istraživanje pokazalo da učenici četvrtih razreda imaju veće preferencije prema glazbi bržeg tempa nego učenici osmih razreda te da učenice u većoj mjeri preferiraju polaganu glazbu. ${ }^{40}$ Iako rezultati prethodnih dvaju navedenih istraživanja pokazuju da učenici starije dobi gube pozitivne stavove prema umjetničkoj glazbi, rezultat istraživanja Dobrote i Obradović ${ }^{41}$ se ne podudara

\footnotetext{
${ }^{35}$ Usp. Patricia SANDERSON, Age and Gender Issues in Adolescent Attitudes to Dance, European Physical Education Review, 7 (2001) 2, 117-136, 117.

${ }^{36}$ Usp. Fiona BANNON, Patricia SANDERSON, Experience Every Moment. Aesthetically Significant Dance Education, Research in Dance Education 1 (2000) 1, 9-26; Derek C. MEAKIN, Patricia SANDERSON, Dance in English Secondary Schools Today, Journal of Aesthetic Education, 17 (1983) 1, 69-83, prema Sanderson, Age and Gender Issues..., 118.

${ }^{37}$ Usp. William O. H. HUGHES, The Effect of High Versus Low Teacher Affect and Active Versus Passive Student Activity During Music Listening on High School General Music Students' Attention, Research perspectives, 2 (1992) 16-18, 16.

${ }^{38}$ Usp. Ralph KEYES, Is there life after high school, Little, Brown, 1976, prema Hughes, The Effect of High Versus..., 36.

${ }^{39}$ Usp. Snježana DOBROTA, Gordana ĆURKOVIĆ, Glazbene preferencije djece mlađe školske dobi, Život i škola, 15-16 (2006) 1-2, 105-113, 105.

${ }^{40}$ Usp. Snježana DOBROTA, Matija MIKELIĆ, Glazbene preferencije učenika prema glazbi različitog tempa, Metodički ogledi, 19 (2012) 2, 137-146, 137.

${ }^{41}$ Usp. Dobrota, Obradović, Stavovi učenika osnovne škole prema glazbi..., 124, 120.
} 
s rezultatima da stav prema umjetničkoj glazbi opada s dobi jer pokazuje da je omiljena aktivnost u nastavi Glazbene kulture učenicima osmih razreda upravo slušanje glazbe, dok je kod učenika četvrtih razreda ono na trećem mjestu najomiljenijih aktivnosti. Primijećena je i razlika omiljenih aktivnosti s obzirom na spol: dječacima je slušanje omiljena aktivnost, dok je djevojčicama ono na drugome mjestu.

Da bi slušanje i upoznavanje glazbe bilo metodički ispravno, zadatci postavljeni učenicima prije slušanja trebaju biti jasni i jednostavni i učitelj treba voditi učenike tijekom slušanja skladbe postavljajući im kratka pitanja. ${ }^{42}$ Nažalost, slušanju glazbe u primarnom obrazovanju posvećuje se svega nekoliko minuta, ono je najčešće pasivno, jednokratno i sadrži neglazbenu motivaciju. ${ }^{43}$

\section{Istraživanje}

\subsection{Istraživački ciljevi i hipoteze}

Cilj istraživanja bio je utvrđivanje preferencija učenika prema različitim aktivnostima i sadržajima u nastavi Glazbene kulture te otkriti postoje li razlike u preferencijama s obzirom na razred, spol učenika te (ne)pohađanje izvannastavne/izvanškolske glazbene aktivnosti. Osim toga, htjelo se istražiti mišljenje učenika o tomu utječu li mediji i nastava glazbe na njihov glazbeni ukus. Istraživanje je polazilo od sljedećih hipoteza:

H1: Vrijeme posvećeno različitim aktivnostima i sadržajima u nastavi Glazbene kulture proporcionalno je preferencijama učenika prema aktivnostima $i$ sadržajima.

H2: Postoji statistički značajna razlika u preferencijama učenika prema aktivnostima i sadržajima u nastavi Glazbene kulture s obzirom na dob, spol te (ne) pohađanje izvannastavne/izvanškolske glazbene aktivnosti.

H3: Ne postoji značajna statistička razlika u mišljenjima učenika o utjecaju medija i nastave glazbe na njihov glazbeni ukus s obzirom na dob ispitanika.

\footnotetext{
${ }^{42}$ Usp. Vera MARTINOVIĆ, Sabina VIDULIN, Umjetnička glazba i oblikovanje kulturnoga identiteta učenika, Školski vjesnik, 64 (2015) 4, 573-588, 576; Elizabeth Ann McANALLY, Meaningful Listening for Middle and High School Students, Teaching Music, 15 (2007) 1, 2226, 22; Patricia SHEHAN CAMPBELL, Deep Listening to the Musical World, Music Educators Journal, 92 (2005) 1, 30-36, 30; Wendy L. SIMS, Sound Approaches to Elementary Music Listening, Music Educators Journal, 77 (1990) 4, 38-42, 38.

${ }^{43}$ Usp. Šulentić Begić, Kujek, Slušanje glazbe u nastavi..., 45; Šulentić Begić, Begić, Otvoreni model nastave glazbe..., 127; Šulentić Begić, Birtić, Otvoreni model nastave glazbene kulture..., 79.
} 


\subsection{Metodologija istraživanja}

\subsubsection{Uzorak i postupak prikupljanja podataka}

Istraživanje, koje se odvijalo tijekom 2018. godine, obuhvatilo je 280 ispitanika, tj. učenike četvrtog, šestog i osmog razreda iz dviju osnovnih škola na području grada Osijeka. Istraživanje je provedeno anonimnim anketiranjem koje je u prosjeku trajalo oko 20 minuta. Učenici su upitnike ispunili na satu Glazbene kulture uz suradnju predmetnih učitelja glazbe. Istraživanje su financirali autori istraživanja. Slijedi opis uzorka učenika (tablica 1).

Tablica 1. Opis uzorka učenika

\begin{tabular}{|l|l|c|c|}
\hline \multirow{2}{*}{ Varijabla } & \multirow{2}{*}{ Kategorije } & \multicolumn{2}{c|}{ Učenici $(\mathbf{N}=\mathbf{2 8 0})$} \\
\cline { 3 - 4 } & & $\mathbf{f}$ & $\mathbf{\%}$ \\
\hline \multirow{2}{*}{ Spol } & Ženski & 139 & 49,6 \\
\cline { 2 - 4 } & Muški & 141 & 50,4 \\
\hline \multirow{3}{*}{ Razred } & Četvrti & 99 & 35,4 \\
\cline { 2 - 4 } & Šesti & 86 & 30,7 \\
\cline { 2 - 4 } & Osmi & 95 & 33,9 \\
\hline
\end{tabular}

Kao što se može vidjeti iz tablice 1, raspodjela učenika prema spolu i prema dobi bila je gotovo ista, $\mathrm{s}$ tim da je nešto manji broj učenika šestog u usporedbi $\mathrm{s}$ učenicima četvrtog i osmog razreda.

\subsubsection{Instrument istraživanja}

Anketni upitnik se sastojao od 20 pitanja kojima su se htjela doznati sociodemografska obilježja ispitanika (spol i dob), kao i mišljenja učenika o različitim aktivnostima i sadržajima u nastavi Glazbene kulture (kako se osjećaju i što najviše vole u nastavi glazbe, pohađaju li neku izvannastavnu/izvanškolsku glazbenu aktivnost, kakav stav imaju prema umjetničkoj glazbi, smatraju li da nastava i mediji utječu na njihov glazbeni ukus). Upitnik je sadržavao pitanja zatvorenog (pitanja jednostrukog i višestrukog izbora te dihotomna pitanja) i otvorenog tipa. Pouzdanost tipa unutarnje konzistencije (Cronbach alfa) za faktor nazvan Preferencije prema aktivnostima $i$ sadržajima iznosi $\alpha=0,71$, što je u granicama prihvatljivosti.

\subsubsection{Statistički postupci}

Upitnik je sadržavao sveukupno 20 čestica. Za obradu kvantitativnih podataka korištena je deskriptivna statistika u obliku apsolutnih i relativnih frekvencija. Također je korišten i Hi-kvadrat test radi utvrđivanja mogućih statistički značajnih razlika u mišljenjima između učenika s obzirom na spol i dob. Kvantitativni podatci obrađeni su računalnim programom SPSS. 


\subsection{Rezultati i rasprava}

Na početku upitnika učenici su trebali odgovoriti na pitanje: Voliš li nastavu Glazbene kulture? (tablica 2).

Tablica 2. Stav prema predmetu s obzirom na razred

\begin{tabular}{|l|c|c|c|c|c|}
\hline \multirow{3}{*}{ Razred } & \multicolumn{4}{|c|}{ Voliš li nastavu Glazbene kulture? } & \multirow{2}{*}{ Učenici } \\
\cline { 2 - 5 } & \multicolumn{2}{|c|}{ Da } & \multicolumn{2}{c|}{ Ne } & (N = 280) \\
\cline { 2 - 5 } & $\mathbf{f}$ & $\mathbf{\%}$ & $\mathbf{f}$ & $\mathbf{\%}$ & 99 \\
\hline \multirow{2}{*}{$\begin{array}{l}\text { Četvrti } \\
\text { Sesti }\end{array}$ Osmi } & 80 & 80,8 & 19 & 19,2 & 86 \\
\cline { 2 - 5 } & 69 & 80,2 & 17 & 19,8 & 95 \\
\hline Ukupno & 60 & 63,2 & 35 & 36,8 & 280 \\
\hline
\end{tabular}

Dakle većina učenika $(74,6 \%)$ voli nastavu glazbe. Hi-kvadrat testom nije utvrđena značajnija statistička razlika između učenica i učenika s obzirom na stav prema nastavnom predmetu, no treba naglasiti da se 71 učenik izjasnio da ne voli nastavu Glazbene kulture. Ujedno, broj učenika koji ne vole nastavu Glazbene kulture povećava se u višim razredima. Statistički značajna razlika nije postojala, no Hi-kvadrat testom $\mathrm{c}^{2}(\mathrm{~N}=280)=10,03$ dobivena je vrijednost $p=0,07$, što je blizu granice statističke značajnosti. Negativniji stav učenika prema nastavi Glazbene kulture viših razreda možda se može objasniti utjecajem medija i vršnjaka. ${ }^{44}$ Medije je teško kontrolirati i zbog toga je njihov utjecaj mnogo veći od utjecaja drugih elemenata. ${ }^{45}$ Osim toga, negativniji stav starijih učenika može biti posljedica neprovođenja suvremene nastavne paradigme »nastave usmjerene na učenika «, ${ }^{46}$ izostanka povezanosti škole, obiteljskog doma i društvene zajednice kada je u pitanju nastava glazbe ${ }^{47}$ te nastave glazbe koja je usmjerena na isključivo umjetničku glazbu, a ne i popularnu koja je prisutna u neformalnom učenju glazbe..$^{48}$

Sa svrhom provjere hipoteze $\mathrm{H} 1$ koja je glasila Vrijeme posvećeno različitim aktivnostima $i$ sadržajima u nastavi Glazbene kulture proporcionalno je preferencijama učenika prema aktivnostima $i$ sadržajima, ispitanicima su po-

\footnotetext{
${ }^{44}$ Usp. Dobrota, Ćurković, Glazbene preferencije djece..., 109.

${ }^{45}$ Usp. Vlasta ILIŠIN, Mediji u slobodnom vremenu djece i komunikacija o medijskim sadržajima, Medijska istraživanja, 9 (2003) 2, 9-34, 14.

${ }^{46}$ Usp. Natassa ECONOMIDOU STAVROU, The music curriculum as »received « by children. Evidence from Cyprus primary schools, British Journal of Music Education, 23 (2006) 2, 187 204, 187.

${ }^{47}$ Usp. Nita TEMMERMAN, Children's participation in music: connecting the cultural contexts - an Australian perspective, British Journal of Music Education, 22 (2005) 2, 113-123, 113.

${ }^{48}$ Usp. Lucy GREEN, How popular musicians learn. A way ahead for music education, Hampshire, Aldershot, 2002, prema Peter DEVRIES, What We Want. The Music Preferences of Upper Primary School Students and the Ways They Engage with Music, Australian Journal of Music Education, 1 (2010) 3-16, 4.
} 
stavljena pitanja: Što najviše radite u nastavi Glazbene kulture? i Što najviše voliš u nastavi Glazbene kulture? Učenicima su bili ponuđeni sljedeći odgovori: pjevanje, sviranje, glazbeno stvaralaštvo, glazbene igre, slušanje glazbe i glazbeno opismenjivanje uz mogućnost da pod nešto drugo dopišu odgovor koji nije bio ponuden (tablica 3).

Tablica 3. Mišljenja učenika s obzirom na zastupljenost i preferencije prema aktivnostima i sadržajima

\begin{tabular}{|l|c|c|c|c|}
\hline \multirow{2}{*}{$\begin{array}{l}\text { Aktivnosti i sadržaji u nastavi } \\
\text { Glazbene kulture }\end{array}$} & \multicolumn{4}{|c|}{ Mišljenje učenika (N = 280) } \\
\cline { 2 - 5 } & \multicolumn{2}{|c|}{ Zastupljenost } & \multicolumn{2}{c|}{ Preferencije } \\
\cline { 2 - 5 } & $\mathbf{f}$ & $\mathbf{\%}$ & $\mathbf{f}$ & $\mathbf{\%}$ \\
\hline Pjevanje & 155 & 55,4 & 158 & 56,4 \\
\cline { 2 - 5 } $\begin{array}{l}\text { Sviranje } \\
\text { Glazbeno stvaralaštvo }\end{array}$ & 2 & 0,7 & 10 & 3,6 \\
\cline { 2 - 5 } $\begin{array}{l}\text { Glazbene igre } \\
\text { Slušanje glazbe }\end{array}$ & - & - & 3 & 1,1 \\
\cline { 2 - 5 } Glazbeno opismenjivanje & - & - & 18 & 6,4 \\
\cline { 2 - 5 } Nešto drugo & 45 & 16,1 & 75 & 26,8 \\
\cline { 2 - 5 } & 39 & 13,9 & 3 & 1,1 \\
\cline { 2 - 5 } & 39 & 13,9 & 13 & 4,6 \\
\hline
\end{tabular}

Da se u nastavi najviše pjeva odgovorilo je 55,4 \% učenika, $16,1 \%$ navelo je slušanje, a 13,9 \% glazbeno opismenjivanje (tablica 3). S obzirom na njihove preferencije, najomiljenija aktivnost je pjevanje, a zatim slijedi slušanje. Rezultat je djelomično u skladu s rezultatima prijašnjeg istraživanja omiljenih aktivnosti i sadržaja u nastavi glazbe, ${ }^{49} \mathrm{u}$ kojem se na prvom i drugom mjestu nalaze iste aktivnosti. $\mathrm{U}$ istom istraživanju se na trećem mjestu nalazi sviranje, a u našem glazbene igre. Rezultati prijašnjih istraživanja pokazuju da se u nastavi Glazbene kulture voli pjevati. ${ }^{50}$ Učenici smatraju da je pjevanje laka i zabavna aktivnost, da su im pjesme koje pjevaju na satu Glazbene kulture zanimljive te da ovom aktivnošću dobivaju dobre ocjene. ${ }^{51}$ Niske preferencije prema aktivnosti sviranja ne začuđuju jer su škole slabo opremljene instrumentima. ${ }^{52}$ Treba naglasiti da je upitna kvaliteta aktivnosti sviranja koju je moguće ostvariti $u$ okviru redovite nastave Glazbene kulture, pa čak i u slučaju da je škola opremljena instrumentima. Glazbeno opismenjivanje i glazbeno stvaralaštvo nalaze se pri samom dnu preferencija učenika. Stoga bi trebalo voditi računa da se navedeni sadržaji i aktivnosti ne nameću učenicima. Također, $13,9 \%$ učenika je pod nešto drugo izjavilo da na satu najviše pišu u bilježnicu.

\footnotetext{
${ }^{49}$ Usp. Dobrota, Obradović, Stavovi učenika osnovne škole prema glazbi..., 127.

${ }^{50}$ Usp. Pavel ROJKO, Kriza glazbene kulture u školi i mogućnosti njezina prevladavanja (neobj. dokt. rad), Zagreb, Filozofski fakultet, 1988; Antoaneta RADOČAJ-JERKOVIĆ, Pjesma i pjevanje u općeobrazovnoj školi (magistarski rad), Zagreb, Muzička akademija u Zagrebu, Filozofski fakultet u Zagrebu, 2009, prema Antoaneta RADOČAJ-JERKOVIĆ, Pjevanje u nastavi glazbe, Osijek, Umjetnička akademija u Osijeku, 2017, 80.

${ }^{51}$ Usp. Radočaj-Jerković, Pjevanje u nastavi glazbe..., 84.

${ }^{52}$ Usp. Dobrota, Obradović, Stavovi učenika osnovne škole prema glazbi..., 120.
} 
Zaključno, s obzirom na navedeno, hipoteza H1 koja je glasila Vrijeme posvećeno različitim aktivnostima $i$ sadržajima u nastavi Glazbene kulture proporcionalno je preferencijama učenika prema aktivnostima $i$ sadržajima je potvrđena. Aktivnosti sviranja, glazbenih igara i slušanja glazbe trebaju zauzimati više mjesta u nastavi, dok opismenjivanje te druge aktivnosti (poput pisanja u bilježnicu) treba smanjiti jer se nastavni sadržaji ionako već nalaze u udžbenicima, a vrijeme posvećeno navedenim aktivnostima i sadržajima nije proporcionalno preferencijama učenika. Ujedno, lako je uočiti da nepostojanje glazbenog stvaralaštva u nastavi Glazbene kulture ni najmanje ne smeta učenike, što i ne začuđuje s obzirom na istraživanje Dobrote i Obradović, ${ }^{53}$ prema kojem glazbeno stvaralaštvo nije omiljena aktivnost kod učenika, tj. na zadnjem je mjestu: od sveukupno 145 učenika, samo tri učenika su navedenu aktivnost navela kao omiljenu.

Nadalje, radi provjere hipoteze $\mathrm{H} 2$ Postoji statistički značajna razlika u preferencijama učenika prema aktivnostima i sadržajima u nastavi Glazbene kulture s obzirom na dob, spol te (ne)pohadanje izvannastavne/izvanškolske glazbene aktivnosti, uspoređeni su dobiveni rezultati (tablica 4).

Tablica 4. Usporedba preferencija prema aktivnostima i sadržajima s obzirom na dob

\begin{tabular}{|l|c|c|c|c|c|c|c|c|c|}
\hline \multirow{2}{*}{ Razred } & \multicolumn{6}{|c|}{ Preferencije prema aktivnostima i sadržajima } & \multirow{2}{*}{ Ukupno } \\
\cline { 2 - 10 } \multicolumn{2}{|c|}{} & pjevanje & sviranje & $\begin{array}{c}\text { stvaralaš- } \\
\text { tvo }\end{array}$ & igre & slušanje & $\begin{array}{c}\text { opisme- } \\
\text { njivanje }\end{array}$ & drugo & \\
\hline \multirow{2}{*}{ Četvrti } & $\mathrm{f}$ & 67 & 7 & 0 & 10 & 11 & 3 & 1 & 99 \\
\cline { 2 - 10 } & $\%$ & 67,7 & 7,1 & 0,0 & 10,1 & 11,1 & 3,0 & 1,0 & 100,0 \\
\hline \multirow{2}{*}{ Šesti } & $\mathrm{f}$ & 45 & 1 & 0 & 5 & 33 & 0 & 2 & 86 \\
\cline { 2 - 10 } & $\%$ & 52,3 & 1,2 & 0,0 & 5,8 & 38,4 & 0,0 & 2,3 & 100,0 \\
\hline \multirow{2}{*}{ Osmi } & $\mathrm{f}$ & 46 & 2 & 3 & 3 & 31 & 0 & 10 & 95 \\
\cline { 2 - 10 } & $\%$ & 48,4 & 2,1 & 3,2 & 3,2 & 32,6 & 0,0 & 10,5 & 100,0 \\
\hline \multirow{2}{*}{ Ukupno } & $\mathrm{f}$ & 158 & 10 & 3 & 18 & 75 & 3 & 13 & 280 \\
\cline { 2 - 10 } & $\%$ & 56,4 & 3,6 & 1,1 & 6,4 & 26,8 & 1,1 & 4,6 & 100,0 \\
\hline
\end{tabular}

Većina učenika, sveukupno gledajući, najviše preferira pjevanje u nastavi Glazbene kulture. Zatim slijedi slušanje, a nakon toga glazbene igre. Od 280 učenika svega tri su navela da im je najdraže glazbeno stvaralaštvo i opismenjivanje. Iako se na prvi pogled čini da su preferencije učenika četvrtih, šestih i osmih razreda vrlo slične, ipak su Hi-kvadrat testom utvrđene i statističke značajne razlike usporedbom pojedinih razreda. Tako je usporedbom četvrtih i šestih razreda Hi-kvadrat testom dobivena vrijednost $c^{2}=24,03 ;(p<0,001)$, te pri usporedbi četvrtih i osmih razreda $c^{2}=33,27 ;(p<0,001)$.

\footnotetext{
${ }^{53}$ Usp. Dobrota, Obradović, Stavovi učenika osnovne škole prema glazbi..., 120.
} 
Rezultat je djelomično u skladu s prijašnjim istraživanjem čiji rezultati govore da su učenicima četvrtih razreda omiljene aktivnosti pjevanje, sviranje te slušanje, dok su učenicima osmih razreda omiljene aktivnosti slušanje, pjevanje i sviranje. ${ }^{54}$ Smanjivanje preferencije prema pjevanju odrastanjem može se objasniti podatkom da učenici s porastom dobi imaju manje entuzijazma za pjevanje. ${ }^{55}$ Iako je redoslijed omiljenih aktivnosti u svim razredima jednak, zaključuje se da postoji statistički značajna razlika s obzirom na dob.

Također, u okviru provjere druge hipoteze uspoređeni su dobiveni rezultati s obzirom na spol ispitanika (tablica 5).

Tablica 5. Usporedba preferencija prema aktivnostima i sadržajima s obzirom na spol

\begin{tabular}{|c|c|c|c|c|c|c|c|c|c|}
\hline \multirow{2}{*}{ Spol } & \multicolumn{6}{|c|}{ Preferencije prema aktivnostima i sadržajima } & \multirow{2}{*}{ Ukupno } \\
\cline { 2 - 10 } & & pjevanje & sviranje & $\begin{array}{c}\text { stvaralaš- } \\
\text { tvo }\end{array}$ & igre & slušanje & $\begin{array}{c}\text { opisme- } \\
\text { nji-vanje }\end{array}$ & drugo & \\
\hline \multirow{2}{*}{ Muški } & $\mathrm{f}$ & 69 & 6 & 1 & 9 & 43 & 1 & 12 & 141 \\
\cline { 2 - 10 } & $\%$ & 48,9 & 4,3 & 0,7 & 6,4 & 30,5 & 0,7 & 8,5 & 100,0 \\
\hline \multirow{2}{*}{ Ženski } & $\mathrm{f}$ & 89 & 4 & 2 & 9 & 32 & 2 & 1 & 139 \\
\cline { 2 - 10 } & $\%$ & 64,0 & 2,9 & 1,4 & 6,5 & 23,0 & 1,4 & 0,7 & 100,0 \\
\hline \multirow{2}{*}{ Ukupno } & $\mathrm{f}$ & 158 & 10 & 3 & 18 & 75 & 3 & 13 & 280 \\
\cline { 2 - 10 } & $\%$ & 56,4 & 3,6 & 1,1 & 6,4 & 26,8 & 1,1 & 4,6 & 100,0 \\
\hline
\end{tabular}

Najviše učenika i učenica preferira pjevanje, zatim slušanje i nakon toga glazbene igre, a najmanje glazbeno opismenjivanje i glazbeno stvaralaštvo. Ipak, Hi-kvadrat testom $\left(c^{2}=14,51\right)$ utvrđena je statistički značajnija razlika između učenika $(p<0,05)$. Rezultat prijašnjeg istraživanja pokazuje da najviše učenika preferira slušanje, a tek onda pjevanje i zatim sviranje. Rezultati učenica sličniji su rezultatu ovog istraživanja jer im je omiljeno također pjevanje, a zatim slijede slušanje i sviranje. ${ }^{56}$ Slabiji je interes učenika prema aktivnosti pjevanja očekivan..$^{57}$

Konačno, a opet radi provjere druge hipoteze, uspoređeni su dobiveni rezultati s obzirom na to pohađaju li učenici neku izvannastavnu i/ili izvanškolsku glazbenu aktivnost (tablica 6).

Zanimljivo, gotovo je isti broj učenika koji pohađa i onih koji ne pohađa neku izvannastavnu/izvanškolsku aktivnost (tablica 6). Obje skupine učenika (oni koji polaze neku izvannastavnu/izvanškolsku aktivnost i oni koji je ne polaze) preferiraju aktivnost pjevanja. No, slušanje glazbe u nastavi više preferiraju učenici koji ne polaze takvu aktivnost. I ovdje je utvrđena statistički značajnija razlika $(\mathrm{p}<0,05)$.

\footnotetext{
${ }^{54}$ Usp. isto, 124.

${ }^{55}$ Usp. Eckhardt, Lück, Das Petitium nach dem Schulmusikunterricht..., 367.

${ }^{56}$ Usp. Dobrota, Obradović, Stavovi učenika osnovne škole prema glazbi..., 120.

${ }^{57}$ Usp. Radočaj-Jerković, Pjevanje u nastavi glazbe..., 83.
} 
Tablica 6. Usporedba preferencija prema aktivnostima i sadržajima s obzirom na (ne) pohađanje izvannastavne/izvanškolske aktivnosti

\begin{tabular}{|c|c|c|c|c|c|c|c|c|c|}
\hline \multirow{2}{*}{\multicolumn{2}{|c|}{$\begin{array}{c}\text { Pohađanje } \\
\text { izvannastav- } \\
\text { ne/izvan- } \\
\text { školske } \\
\text { aktivnosti }\end{array}$}} & \multicolumn{7}{|c|}{ Preferencije prema aktivnostima i sadržajima } & \multirow{3}{*}{$\begin{array}{c}\text { Ukupno } \\
139 \\
\end{array}$} \\
\hline & & \multirow{2}{*}{$\begin{array}{c}\text { pjevanje } \\
87 \\
\end{array}$} & \multirow{2}{*}{$\begin{array}{c}\text { sviranje } \\
6\end{array}$} & \multirow{2}{*}{$\begin{array}{c}\begin{array}{c}\text { stvaralaš- } \\
\text { tvo }\end{array} \\
2\end{array}$} & \multirow{2}{*}{$\begin{array}{c}\text { igre } \\
9\end{array}$} & \multirow{2}{*}{$\begin{array}{c}\text { slušanje } \\
31 \\
\end{array}$} & \multirow{2}{*}{$\begin{array}{c}\begin{array}{c}\text { opisme- } \\
\text { nji-vanje }\end{array} \\
3 \\
\end{array}$} & \multirow{2}{*}{$\begin{array}{c}\text { drugo } \\
1\end{array}$} & \\
\hline & $\mathrm{f}$ & & & & & & & & \\
\hline $\mathrm{Da}$ & $\%$ & 62,6 & 4,3 & 1,4 & 6,5 & 22,3 & 2,2 & 0,7 & 100,0 \\
\hline \multirow{2}{*}{$\mathrm{Ne}$} & $\mathrm{f}$ & 71 & 4 & 1 & 9 & 44 & 0 & 12 & 141 \\
\hline & $\%$ & 50,4 & 2,8 & 0,7 & 6,4 & 31,2 & 0,0 & 8,5 & 100,0 \\
\hline \multirow{2}{*}{ Ukupno } & $\mathrm{f}$ & 158 & 10 & 3 & 18 & 75 & 3 & 13 & 280 \\
\hline & $\%$ & 56,4 & 3,6 & 1,1 & 6,4 & 26,8 & 1,1 & 4,6 & 100,0 \\
\hline
\end{tabular}

Analizirajući koje izvannastavne/izvanškolske aktivnosti su učenici polazili/polaze dobiveni su sljedeći podatci: zbor pohađa 68 učenika $(24,3 \%)$, orkestar $2(0,7 \%)$, glazbenu školu 26 (9,3\%), ritmiku/ples $52(18,6 \%)$ te tečaj sviranja $25(8,9 \%)$. Rezultat da učenici najviše preferiraju aktivnost pjevanja ne čudi jer najveći broj učenika polazi pjevački zbor. Iako je čak 51 učenik naveo da je polazio/polazi glazbenu školu ili tečaj sviranja, samo 10 ih je sveukupno navelo sviranje kao omiljenu aktivnost. Pretpostavljamo da je razlog činjenica da sviranje u nastavi Glazbene kulture nije sviranje na razini na kojoj se ono odvija u glazbenim školama ili na tečajevima sviranja. Rezultat da slušanje glazbe više preferiraju učenici koji ne polaze izvannastavnu/izvanškolsku aktivnost pokazuje da učenici, pogotovo oni koji su manje okruženi glazbom, ipak žele slušati glazbu. Učiteljeva je dužnost da im to omogući, a to ne bi trebalo biti problem s obzirom na to da bi upravo navedena aktivnost trebala biti i dominantna aktivnost nastave glazbe. ${ }^{58}$ I u ovom slučaju je Hi-kvadrat testom $\left(c^{2}=16,9\right)$ utvrđena statistički značajna razlika učeničkih preferencija $(p<0,05)$.

Iz navedenih rezultata (tablice 4-6) može se zaključiti da su utvrđene značajne statističke razlike među učenicima u preferencijama prema aktivnostima i sadržajima u nastavi Glazbene kulture. Stoga je hipoteza H2, koja je glasila Postoji statistički značajna razlika u preferencijama učenika prema aktivnostima i sadržajima u nastavi Glazbene kulture s obzirom na dob, spol te (ne) pohađanje izvannastavne/izvanškolske glazbene aktivnosti potvrđena.

Naposljetku, a radi provjere hipoteze H3 Ne postoji značajna statistička razlika u mišljenjima učenika o utjecaju medija i nastave glazbe na njihov glazbeni ukus sobzirom na dob ispitanika, učenicima su postavljena pitanja na koja su odgovorili ovako (tablice 7-8):

${ }^{58}$ Usp. Kurikulum..., 5. 
Tablica 7. Mišljenje učenika o utjecaju medija na njihov glazbeni ukus

\begin{tabular}{|c|c|c|c|c|}
\hline \multirow{2}{*}{\multicolumn{2}{|c|}{ Razred }} & \multicolumn{2}{|c|}{ Utjecaj medija na glazbeni ukus } & \multirow{3}{*}{$\begin{array}{c}\text { Ukupno } \\
99\end{array}$} \\
\hline & & \multirow{2}{*}{$\begin{array}{l}\text { da } \\
46\end{array}$} & \multirow{2}{*}{$\begin{array}{l}\text { ne } \\
53\end{array}$} & \\
\hline & $f$ & & & \\
\hline Cetvrti & $\%$ & 46,5 & 53,5 & 100,0 \\
\hline \multirow{2}{*}{ Šesti } & $\mathrm{f}$ & 51 & 35 & 86 \\
\hline & $\%$ & 59,3 & 40,7 & 100,0 \\
\hline \multirow{2}{*}{ Osmi } & $f$ & 52 & 43 & 95 \\
\hline & $\%$ & 54,7 & 45,3 & 100,0 \\
\hline \multirow{2}{*}{ Ukupno } & $f$ & 149 & 131 & 280 \\
\hline & $\%$ & 53,2 & 46,8 & 100,0 \\
\hline
\end{tabular}

Na pitanje misle li da mediji utječu na njihov glazbeni ukus podjednako su odgovorili učenici četvrtih, šestih i osmih razreda, a takav je i sveukupan odnos između pozitivnog i negativnog mišljenja. Nije utvrđena statistički značajnija razlika između učenika različitih razreda $(p>0,05)$. Potencijalni utjecaj medija je sve veći svakim novim naraštajem jer je prisutnost medija sve bogatija, zbog čega su najmlađa djeca najranjivija skupina - što su djeca mlađa, imaju manju sposobnost zaštititi se od medija. ${ }^{59}$

Tablica 8. Mišljenje učenika o utjecaju nastave Glazbene kulture na njihov glazbeni ukus.

\begin{tabular}{|c|c|c|c|c|}
\hline \multirow{2}{*}{\multicolumn{2}{|c|}{ Razred }} & \multicolumn{2}{|c|}{ Utjecaj nastave na glazbeni ukus } & \multirow{3}{*}{$\begin{array}{c}\text { Ukupno } \\
99\end{array}$} \\
\hline & & \multirow{2}{*}{$\begin{array}{l}\text { da } \\
64 \\
\end{array}$} & \multirow{2}{*}{$\begin{array}{l}\text { ne } \\
35 \\
\end{array}$} & \\
\hline Čturt & $f$ & & & \\
\hline Cetvrti & $\%$ & 64,6 & 35,4 & 100,0 \\
\hline \multirow{2}{*}{ Šesti } & $\mathrm{f}$ & 44 & 42 & 86 \\
\hline & $\%$ & 51,2 & 48,8 & 100,0 \\
\hline \multirow{2}{*}{ Osmi } & $f$ & 17 & 78 & 95 \\
\hline & $\%$ & 17,9 & 82,1 & 100,0 \\
\hline \multirow{2}{*}{ Ukupno } & $\mathrm{f}$ & 125 & 155 & 280 \\
\hline & $\%$ & 44,6 & 55,4 & 100,0 \\
\hline
\end{tabular}

Vidljivo je da većina učenika četvrtih razreda smatra da nastava Glazbene kulture utječe na njihov glazbeni ukus. Istodobno, istog je mišljenja otprilike polovica učenika učenika šestih razreda, a osmih svega $17,9 \%$. Sasvim očekivano, utvrđena je statistički značajna razlika u odgovorima ispitanika $(p<0,001)$. Učenici nastavu glazbe ne povezuju s razvijanjem glazbenog ukusa jer nisu svjesni utjecaja umjetničke glazbe. Može se zaključiti da se mišljenje o utjecaju nastave Glazbene kulture na glazbeni ukus smanjuje odrastanjem.

\footnotetext{
${ }^{59}$ Usp. Ilišin, Mediji u slobodnom vremenu..., 14.
} 
S obzirom na dobivene rezultate (tablice 7-8) hipoteza H3 Ne postoji značajna statistička razlika u mišljenjima učenika o utjecaju medija $i$ nastave glazbe na njihov glazbeni ukus s obzirom na dob ispitanika djelomično je potvrđena.

\section{Zaključak}

Analizom anketnog upitnika utvrđeno je da učenici imaju pozitivan stav prema nastavi Glazbene kulture, iako se on smanjuje odrastanjem, što se može objasniti utjecajem medija i vršnjaka. ${ }^{60}$ Učenici najviše preferencija pokazuju prema pjevanju, a upravo je ono najviše zastupljeno u nastavi glazbe, a i najveći broj učenika polazi izvannastavnu/izvanškolsku aktivnost pjevanja, tj. pjevački zbor. Druge nastavne aktivnosti, sviranje, glazbene igre i slušanje glazbe, prema preferencijama učenika, nisu dovoljno zastupljene, iako su uz pjevanje, glazbene igre i slušanje glazbe ujedno i aktivnosti koje bi učenici najviše voljeli raditi u nastavi. Suprotno tomu, opismenjivanje i druge aktivnosti (pisanje u bilježnicu) učenicima su najmanje omiljene i trebalo bi ih rjeđe provoditi.

Utvrđeno je da učenici svih ispitanih razreda, tj. četvrtih, šestih i osmih razreda, najviše preferiraju pjevanje, a zatim slušanje glazbe i glazbene igre, iako je razvidno da se preferencije prema pjevanju smanjuju odrastanjem. To se može objasniti činjenicom da učenici starije dobi imaju manje entuzijazma za pjevanje. ${ }^{61}$ Analiza preferencija glazbenih aktivnosti s obzirom na spol učenika pokazuje da se pojedine aktivnosti nalaze na istom mjestu i kod učenica i kod učenika iako je interes učenika prema pjevanju znatno slabiji, što je i očekivano. ${ }^{62}$ Slušanje glazbe više preferiraju učenici koji glazbenu izvannastavnu/ izvanškolsku aktivnost nisu polazili ili je ne polaze, što znači da učenici žele slušati glazbu, a učitelj im u nastavi to treba i omogućiti.

Ne postoji statistički značajna razlika u preferencijama prema aktivnostima i sadržajima s obzirom na to slušaju li učenici u slobodno vrijeme umjetničku glazbu te slušaju li roditelji učenika umjetničku glazbu. Zaključeno je da veći broj roditelja nego učenika sluša umjetničku glazbu, a njihov slab utjecaj na djecu objašnjava se podatkom da »samo 10 do 15 posto djece razgovara s roditeljima o tome što su gledali, slušali ili pročitali«. ${ }^{63}$

Podjednak broj učenika svih ispitanih razreda misli da mediji utječu/ne utječu na njihov glazbeni ukus, iako je vidljivo da je manji broj učenika mlađe dobi svjestan utjecaja medija, što ne čudi jer su najmlađa djeca najranjivija skupina.$^{64}$ Utjecaj medija primjećuje se i u vrsti glazbe koju učenici najviše vole

\footnotetext{
${ }^{60}$ Usp. Dobrota, Curković, Glazbene preferencije djece..., 113.

${ }^{61}$ Usp. Eckhardt, Lück, Das Petitium nach dem Schulmusikunterricht..., 61.

${ }^{62}$ Usp. Radočaj-Jerković, Pjevanje u nastavi glazbe..., 83.

${ }^{63}$ Manca KOŠIR, Nada ZGRABLJIĆ, Rajko RANFIL, Život s medijima, Zagreb, Doron, 1999, prema Ilišin, Mediji u slobodnom vremenu..., 16.

${ }^{64}$ Usp. Ilišin, Mediji u slobodnom vremenu..., 14.
} 
slušati, a to je popularna glazba. Upravo zato što je ona u fokusu njihova slušanja, u nastavi Glazbene kulture učenike treba naučiti razlikovati kvalitetnu od nekvalitetne popularne glazbe. Suprotno stavovima o utjecaju medija, veći broj učenika starije dobi misli da nastava glazba ne utječe na njihov glazbeni ukus. Dakle, možemo zaključiti:

- da učenici imaju pozitivan stav prema nastavi Glazbene kulture i umjetničkoj glazbi, iako ju većina učenika ne sluša u slobodno vrijeme;

- da postoji razlika u preferencijama prema aktivnostima i sadržajima s obzirom na dob i spol učenika i njihovo (ne)pohađanje izvannastavne/ izvanškolske aktivnosti;

- da postoji razlika u preferencijama prema aktivnostima i sadržajima s obzirom na (ne)slušanje umjetničke glazbe u slobodno vrijeme od strane učenika;

- da ne postoji razlika u preferencijama prema aktivnostima i sadržajima s obzirom na roditeljsko (ne)slušanje umjetničke glazbe;

- da podjednak broj učenika misli da mediji te nastava glazbe utječu, odnosno ne utječu na njihov glazbeni ukus;

- da zastupljenost aktivnosti i sadržaja, osim pjevanja, nije proporcionalna učeničkim preferencijama.

Za potpunije sagledavanje problematike moglo bi poslužiti neko buduće istraživanje koje bi uključilo i sustavno promatranje nastave. Time bi se vjerojatno dobila objektivnija slika o učeničkim preferencijama prema aktivnostima i sadržajima u nastavi Glazbene kulture. Ujedno, nadamo se da će, s obzirom na otvoreni kurikulum prema kojem učitelj ima slobodu uzimati u obzir želje i mogućnosti učenika, rezultate ovog istraživanja imati u vidu predmetni učitelji glazbe. Naime, učitelji pri planiranju nastave glazbe trebaju uvažavati njihove interese i stavove prema različitim glazbenim aktivnostima jer su stavovi učenika prema glazbi važan faktor uspješnog učenja i aktivnog bavljenja glazbom. ${ }^{65}$ Glazbene preferencije učenika trebaju se uzeti u obzir prilikom osmišljavanja nastavnih jedinica, izbora glazbe i organiziranja i izvođenja nastave. Naime, glazbene vještine i preferencije glazbi stječu se u ranoj dobi te glazbeni pedagozi igraju veliku ulogu u tom razvoju. ${ }^{66}$ Smatramo da će uvažavajući preferencije učenika prema aktivnostima i sadržajima te uz osluškivanje želja učenika učitelji provoditi kvalitetniju nastavu glazbe, a i učenici će tada pokazati veću motiviranost i entuzijazam.

\footnotetext{
${ }^{65}$ Usp. Temmerman, An investigation of the music activity..., 58.

${ }^{66}$ Kevin DROE, Music Preference and Music Education. A Review of Literature, Update. Applications of Research in Music Education, 24 (2006) 2, 23-32, 30.
} 


\section{Jasna Šulentić Begić* - Amir Begić"**: - Ivana Pušićc**** \\ Students' Preferences Towards Activities and Teaching Content in Music Culture Classes}

\section{Summary}

From the 2019/20 school year Music Culture classes should be implemented according to the Curriculum of the Music Culture for Primary Schools and Musical Arts for Gymnasium curriculum, which will enter all grades of primary school over the course of three years. The curriculum implements an open curriculum that allows teachers to adapt learning and teaching to students' interests and abilities and their own preferences. Within the framework of the study, a study was conducted to identify students' preferences for different activities and content in Music Culture teaching and to find out if there were differences in preferences with regard to class, student gender, and (non)attendance of extracurricular/after-school music activities. The survey, which took place during 2018, included 280 respondents, ie, fourth, sixth and eighth grade students were surveyed. The results show that students have a positive attitude towards teaching Music Culture and that they prefer singing and then listening to music and playing music. However, the representation of activities and content, apart from singing, is not proportional to the students' preferences. The preferences for music activities according to the gender of students show that certain activities are in the same place for both male and female students. Also, listening to music is preferred by students who did not attend or do not attend music extracurricular/after-school music activities. In conclusion, we believe that students' musical preferences should be taken into account when designing teaching units, choosing music, and organizing and conducting classes.

Key words: activities and teaching content, Music Culture classes, open model/ curriculum, students' preferences.

(na engl. prev. Amir Begić)

\footnotetext{
* Jasna Šulentić Begić, PhD, Assoc. Prof., The Academy of Arts and Culture in Osijek; Address: Kralja Petra Svačića 1/F, HR-31000 Osijek, Croatia; E-mail: jsulentic-begic@uaos.hr.

* Amir Begić, PhD, Assist. Prof., The Academy of Arts and Culture in Osijek,; Address: Kralja Petra Svačića 1/F, HR-31000 Osijek, Croatia; E-mail: abegic@uaos.hr.

***: Ivana Pušić, mag. mus., Primary School Ivan Kozarac; Address: Dr. Franje Račkog 30, HR32270 Županja; E-mail: ivana.pusic@hotmail.com.
} 